\title{
Stereotactic body radiotherapy for low-risk prostate cancer: five-year outcomes
}

\author{
Debra E Freeman ${ }^{1 *}$, Christopher R King ${ }^{2}$
}

\begin{abstract}
Purpose: Hypofractionated, stereotactic body radiotherapy (SBRT) is an emerging treatment approach for prostate cancer. We present the outcomes for low-risk prostate cancer patients with a median follow-up of 5 years after SBRT.

Method and Materials: Between Dec. 2003 and Dec. 2005, a pooled cohort of 41 consecutive patients from Stanford, CA and Naples, FL received SBRT with CyberKnife for clinically localized, low-risk prostate cancer. Prescribed dose was 35-36.25 Gy in five fractions. No patient received hormone therapy. Kaplan-Meier biochemical progression-free survival (defined using the Phoenix method) and RTOG toxicity outcomes were assessed.

Results: At a median follow-up of 5 years, the biochemical progression-free survival was $93 \%(95 \% \mathrm{Cl}=84.7 \%$ to 100\%). Acute side effects resolved within 1-3 months of treatment completion. There were no grade 4 toxicities. No late grade 3 rectal toxicity occurred, and only one late grade 3 genitourinary toxicity occurred following repeated urologic instrumentation.

Conclusion: Five-year results of SBRT for localized prostate cancer demonstrate the efficacy and safety of shorter courses of high dose per fraction radiation delivered with SBRT technique. Ongoing clinical trials are underway to further explore this treatment approach.
\end{abstract}

\section{Background}

Prostate cancer is thought to have unique radiobiology, characterized by a low $\alpha / \beta$ ratio relative to surrounding normal tissues [1,2]. A growing body of evidence from clinical studies using hypofractionated radiation provides support that the $\alpha / \beta$ ratio for prostate cancer is lower than that for the bladder and rectum, and that consequently a therapeutic gain could be achieved using fewer, high-dose fractions (see reviews by Dasu [3] and Macias and Biete [4]). High-dose-rate (HDR) brachytherapy can deliver radiation to a tightly constrained treatment volume using large doses per fraction. Recent multi-institutional findings reported by Martinez et al. for early stage prostate cancer show a 5 -year biochemical disease-free survival of about $90 \%$ for HDR brachytherapy, which is comparable to their own lowdose-rate (LDR) brachytherapy outcomes, with lower late toxicity levels [5-7].

\footnotetext{
* Correspondence: dfreeman_md@yahoo.com

'Naples Radiation Oncology, PA, USA

Full list of author information is available at the end of the article
}

Stereotactic body radiotherapy (SBRT) has recently emerged as an alternative technique to deliver hypofractionated radiotherapy to the prostate, comparable in many respects to HDR brachytherapy, but with a noninvasive approach [8-14]. The concept is not entirely novel. In the $1980 \mathrm{~s}$, prostate cancer patients were treated in the United Kingdom with 6 fractions of 6 Gy each, delivered over three weeks. Good disease control with no major early or late morbidity was obtained [15]. Innovations in image-guidance technology, the ability to automatically correct for the movement of the prostate during treatment, and delivery of highly-conformal beam profiles have greatly enhanced the capability of delivering high dose fractions to a well-defined target, with sharp dose fall-off towards the bladder and rectum [16-18].

King et al. at Stanford University began treating lowrisk prostate cancer patients with the CyberKnife system (Accuray Inc., Sunnyvale, CA) in late 2003, using five fractions of 7.25 Gy (total 36.25 Gy). At a median follow-up of 33 months for the first 41 patients, the urethral/rectal toxicity profile was comparable to that

\section{() Biomed Central}


from dose-escalated external beam radiotherapy (EBRT) [12]. Friedland and Freeman et al. in Naples, Florida, began their SBRT program in early 2005, treating lowand intermediate-risk patients with 5 fractions of $7.0 \mathrm{~Gy}$ (total 35 Gy). Outcomes from their first 112 patients showed a biochemical control rate of $97 \%$ at 24 months median follow-up and toxicity similar to or better than published outcomes of EBRT [9].

Given the intense level of interest in academic and community practices, the ramifications for the management of prostate cancer, and the potential positive economic impact on prostate cancer treatments, we felt it would be both timely and of significant value to examine outcomes from patients with the longest follow-up available to date with the aim of determining disease control and toxicity for SBRT at a median of 5 years. In this report, we present for the first time the results from our combined experience.

\section{Materials and methods \\ Patient Characteristics}

The Stanford prostate SBRT program began in December 2003. Eligible patients had newly diagnosed, biopsy-proven prostate cancer presenting with low-risk features. The criteria for low-risk classification included a pre-treatment PSA of $10 \mathrm{ng} / \mathrm{mL}$ or less, Gleason score of $3+3$ or lower and clinical stage T1c or T2a/b. Patients with a Gleason score of $3+4$ were included if present in 2 or fewer cores and involving less than $5 \mathrm{~mm}$ aggregate tumor length. Patients with prior treatment (hormone therapy or transurethral resection of prostate) were excluded. The Naples prospective program began in February 2005. Eligibility criteria were similar to that of the Stanford program, except that it included patients with Gleason scores 3 +4 in addition to those with Gleason scores of $3+3$. For the current study, we included only the Naples patients with Gleason scores of $3+3$ or lower, to increase the homogeneity of this combined study population. Staging work-up included a bone scan and CT scan of the abdomen and pelvis. Both centers had IRB-approval for enrolling patients in their clinical trial.

The current patient cohort consists of consecutively treated patients with the longest follow-up participating in the Stanford [12] and Naples studies [9]. Two patients were lost to follow-up within 12 months of treatment and were not included. Two others died of non-prostate cancer related disease at 12 and 51 months after treatment. This study is therefore composed of 41 patients with a median follow-up of 5 years (4.2-6.2 years). The median patient age was 66 years (range 48 to 83 years). The median initial PSA was $5.6 \mathrm{ng} / \mathrm{mL}$ (range 0.7 to $10 \mathrm{ng} / \mathrm{mL}$ ).

\section{Treatment Planning and Delivery}

Three to four gold fiducial markers were placed in the prostate under transrectal ultrasound guidance for image-guided positioning and motion tracking. Treatment planning CT scans were performed at a slice thickness of $1.25 \mathrm{~mm}$, either on the same day (Stanford) or one week after fiducial placement (Naples). MRI scans were obtained for all Naples patients, with preferred sequences of T2* GRE or T1 post Gd, using a slice thickness of 1-2 mm. Planning CTs were used either alone (Stanford) or fused with MRI images (Naples), to differentiate the prostate and the proximal 1 $\mathrm{cm}$ of the seminal vesicles (the gross tumor volume, or GTV) from the rectum, urogenital diaphragm, bladder, distal seminal vesicles, and other surrounding structures. The clinical target volume consisted of a $3 \mathrm{~mm}$ expansion anteriorly and laterally and a $1 \mathrm{~mm}$ posterior expansion. The planning target volume (PTV) consisted of an additional $2 \mathrm{~mm}$ expansion anteriorly and laterally and $2 \mathrm{~mm}$ posteriorly, to account for errors in target definition and delivery.

All patients were treated with the CyberKnife system, composed of a $6 \mathrm{MV}$ linear accelerator mounted on a robotic arm, with two orthogonal kilovoltage X-ray imagers that provide real-time stereoscopic image guidance and automatic correction for movements of the prostate throughout treatment. Typically, 150-200 non-coplanar beams were delivered in each treatment session. Patient positioning and target tracking were accomplished by registering the location of the fiducials in the real time images to their location in the planning CT. The robot automatically corrected the accelerator's aim to account for both translational and rotational movement of the patient or prostate during the treatment.

Treatment for the Stanford patients consisted of 5 fractions of 7.25 Gy for a total dose of 36.25 Gy. The prescription dose covered at least $95 \%$ of the planning target volume, normalized to the $88-92 \%$ isodose line. The rectal dose-volume goals were $<50 \%$ of the rectum receiving $50 \%$ of the prescribed dose, $<20 \%$ receiving $80 \%$ of the dose, $<10 \%$ receiving $90 \%$ of the dose, and $<5 \%$ receiving $100 \%$ of the dose. The Naples patients received 5 fractions of 7 Gy each, for a total dose of 35 Gy. The planning objective was also to deliver the prescribed dose to at least $95 \%$ of the PTV. For the rectum, the V36 Gy constraint was $<1 \mathrm{~cm}^{3}$; for the bladder, the V37 Gy was $<10 \mathrm{~cm}^{3}$. The Stanford rectal dose-volume guidelines were followed whenever possible. Treatments were given over 5 consecutive days for all but 3 patients in the combined cohort.

\section{Follow-up and Toxicity Scoring}

Patients were followed every 3 months during the first year and every 6-12 months thereafter. PSA levels were 
obtained at each follow-up. Toxicity and quality of life measures for Stanford patients were assessed using the EPIC scale. Naples patients were assessed with the American Urological Association (AUA) and Sexual Health Inventory for Men (SHIM) surveys. Toxicities were subsequently scored based on Radiation Therapy Oncology Group (RTOG) urinary and rectal toxicity criteria [19], and toxicities requiring intervention were noted. (The authors acknowledge that the RTOG scoring system may be insensitive to subtle changes in urinary or bowel function.) Biochemical failure was assessed using the nadir+2 (Phoenix) definition [20].

\section{Results}

PSA Response

The 5-year biochemical progression-free survival rate was $92.7 \%$ ( $95 \% \mathrm{CI}=84.7 \%$ to $100 \%$, Figure 1$)$. PSA fell from a pre-treatment mean $( \pm \mathrm{SD})$ of $5.4 \pm 2.4 \mathrm{ng} / \mathrm{ml}$ to a mean post-treatment value of $0.34 \pm 0.35 \mathrm{ng} / \mathrm{ml}$ at last follow-up for non-recurring patients. Median PSA nadir was $0.3 \mathrm{ng} / \mathrm{ml}$. Comparing non-recurring Stanford patients (treated with 36.25 Gy) to Naples patients (treated with $35 \mathrm{~Gy}$ ), the mean PSA at last follow-up was significantly lower for the Stanford group $(0.18 \pm 0.14$ $\mathrm{ng} / \mathrm{ml}$ vs. $0.51 \pm 0.46 \mathrm{ng} / \mathrm{ml}, p=0.002)$. The mean follow-up for the Stanford patients was about 4.5 months longer than for the Naples patients (5.17 vs. 4.78 years). Three patients developed biochemical progression at 33, 37 and 42 months, respectively. Two patients received the 35 Gy dose; the third received 36.25 Gy. In each case, biopsy confirmed pathologic evidence of malignancy within the prostate gland and a negative metastatic work-up. The remaining patients continued to have stable or declining PSA levels at last follow-up.

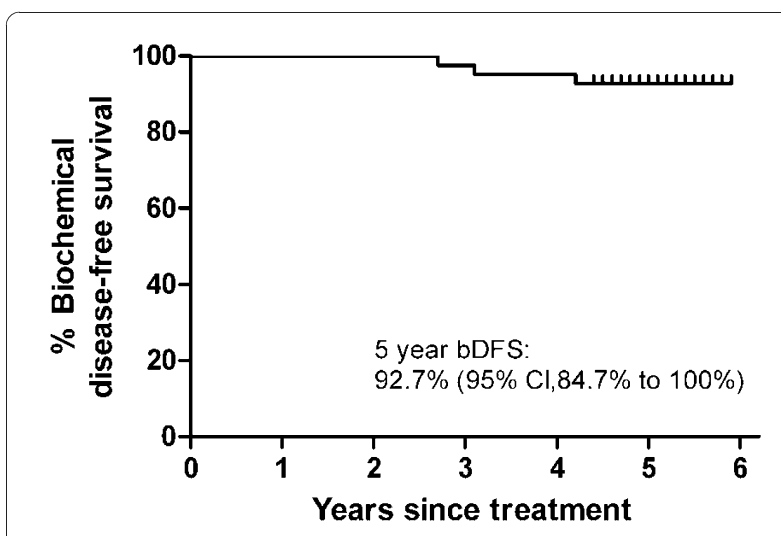

Figure 1 Kaplan-Meier biochemical disease-free survival curve after SBRT for prostate cancer. Median follow-up is 5-years. Three of the 41 patients recurred, at 33, 37 and 42 months post-treatment. Tick marks indicate censored patients.

\section{Toxicity}

As previously reported, patients tolerated treatments very well, resuming normal activities within one week of completion. Acute symptoms of dysuria, urinary urgency, frequency, nocturia and/or tenesmus typically resolved within one month of treatment completion. Late toxicities are summarized in Table 1. No patient has experienced grade 3 or greater late rectal toxicity. Only one patient developed late grade 3 urinary toxicity following repeated urologic instrumentation, including cystoscopy and urethral dilatation. No urinary incontinence has been observed. Twenty-five percent of patients reported mild (grade 1) and 7\% moderate (grade 2) urinary symptoms following treatment. King et al. [12] previously reported less frequent grade 1-2 urinary toxicity when SBRT treatments were delivered on non-consecutive days (QOD) vs. daily (QD). As the majority of patients in this study received QD treatment, a similar comparison was not possible.

\section{Discussion}

This report demonstrates that SBRT can achieve high rates of durable disease control for patients with lowrisk prostate cancer while resulting in low levels of bladder and rectal toxicity. The current results extend prior independently conducted studies by the authors $[9,12]$, demonstrating the potential of SBRT monotherapy to provide durable disease control with few serious complications in low-risk prostate cancer patients. Our 5-year progression-free survival rate of $93 \%$ compares favorably with that obtained with surgery, LDR or HDR brachytherapy [21-26].

In a recent update of the Stanford experience, which included 67 low-risk patients [27], King et al. succinctly reviewed the rationale for hypofractionation in the management of prostate cancer. At a median follow-up of 2.7 years, the PSA relapse-free survival was $94 \%$, and toxicity was equal to or lower than observed in doseescalation studies. Disease control rates above $90 \%$ are entirely consistent with predictions based on an $\alpha / \beta$ ratio for prostate cancer of $1.5 \mathrm{~Gy}$. Using the linearquadratic radiobiologic model, 36.25 Gy yields an equivalent dose at 2 Gy per fraction, or EQD2, of 91 Gy for this $\alpha / \beta$.

In addition, both disease control and toxicity outcomes with SBRT compare favorably to other treatments for

Table 1 Late urinary and rectal toxicity on the RTOG scale for prostate cancer patients after SBRT

\begin{tabular}{lllll}
\hline RTOG Grade & I & II & III & IV \\
\hline Urinary & $25 \%(10 / 41)$ & $7 \%(3 / 41)$ & $2.5 \%(1 / 41)$ & $0 \%$ \\
\hline Rectal & $\begin{array}{l}13 \% \\
(6 / 41)\end{array}$ & $\begin{array}{l}2.5 \% \\
(1 / 41)\end{array}$ & $0 \%$ & $0 \%$ \\
& & & \\
\hline
\end{tabular}


low-risk prostate cancer. In a study comparing outcomes for radical prostatectomy and IMRT to a dose of at least 72 Gy [28], no significant difference in 5-year biochemical disease-free survival (bDFS) rates was detected for low-risk patients (prostatectomy resulted in a bDFS of $92.8 \%$ vs. $85.3 \%$ for IMRT, $p=0.20$ ). Similar 5 -year bDFS rates, ranging from $76 \%$ to $92 \%$ for radical prostatectomy, $69 \%$ to $89 \%$ for external beam radiotherapy at doses of 66 to $72 \mathrm{~Gy}$, and $83 \%$ to $88 \%$ for seed brachytherapy, have been reported in retrospective comparisons of these various treatments [21-26]. A recent report of a multiinstitutional retrospective study comparing HDR brachytherapy to seed brachytherapy showed bDFS to be about $90 \%$ for both modalities. Somewhat higher 5 -year bDFS rates, in the $92-95 \%$ range, have been obtained in other studies of surgery, high-dose and hypofractionated EBRT, and seed brachytherapy for low-risk patients [29-32]. Thus, the 5-year bDFS of $92.7 \%$ obtained in the current study is clearly within the range of disease control expected using modern surgical and high-dose radiation techniques.

In the coming years, the long-term outcomes of several other studies of SBRT for organ-confined prostate cancer will be reported. Katz et al. reported 3-year results on 304 patients with low- and intermediate-risk disease, with favorable outcomes [11]. An update with 42 months median follow up was presented at ASTRO 2010 [33], and 5-year data from this study should be available in 2011. An additional 114 low-intermediate risk prostate patients were treated with SBRT in Naples in 2006, so that data will reach 5-year maturity next year. Acute toxicity from a prospective study underway at the University Hospitals Case Medical Center were presented at the 2009 ASCO meeting [34]. Georgetown has also treated prostate cancer using SBRT; early data were presented at the 2010 ASCO meeting [35]. Two prospective studies funded by Accuray, examining the effects of delivering either a homogeneous, EBRT-like dose distribution or an HDR-like, heterogeneous distribution [10] should complete enrollment in the next 6 months, adding another 600 patients to the collective data pool. A phase III study comparing 12-fraction versus 5-fraction SBRT for localized prostate cancer is currently under review by the RTOG, and a proposed, phase III study from the University of Miami will compare extended fractionation (26 fractions) versus accelerated hypofractionation (5 fractions) for low-intermediate risk disease. As data from these various studies mature, we will develop a clearer picture of long-term outcomes following SBRT.

\section{Conclusion}

The current analysis is the first report of 5-year outcomes of SBRT for low-risk prostate cancer, and biochemical disease control is comparable to other available therapies, with equal to or better toxicity profiles. In addition, the treatment can be completed in a time period that is notably shorter (1-2 weeks) than conventional radiotherapy (8-9 weeks) and neither hospitalization nor surgical recovery is involved. These characteristics of SBRT may benefit patients by reducing travel costs and lost work time, allowing a more immediate return to normal, daily routines, and potentially reducing health care costs. We look forward to future multicenter studies that will examine outcomes with this treatment approach.

\section{Author details}

${ }^{1}$ Naples Radiation Oncology, PA, USA. ${ }^{2}$ Department of Radiation Oncology, UCLA School of Medicine, CA, USA.

\section{Authors' contributions}

Both authors contributed equally to the conduct of the study and the contribution of patient data to the analysis. DF conducted analyses and wrote the initial draft of the paper. Both authors read and approved the final manuscript.

\section{Competing interests}

DF has received reimbursement as a consultant/employee for Accuray, Inc. CK has no financial conflicts of interest.

Received: 13 October 2010 Accepted: 10 January 2011

Published: 10 January 2011

\section{References}

1. Brenner DJ, Hall EJ: Fractionation and protraction for radiotherapy of prostate carcinoma. Int J Radiat Oncol Biol Phys 1999, 43:1095-1101.

2. Fowler JF, Ritter MA, Chappell RJ, Brenner DJ: What hypofractionated protocols should be tested for prostate cancer? Int J Radiat Oncol Biol Phys 2003, 56:1093-1104.

3. Dasu A: Is the alpha/beta value for prostate tumours low enough to be safely used in clinical trials? Clin Oncol (R Coll Radiol) 2007, 19:289-301.

4. Macias $V$, Biete $A$ : Hypofractionated radiotherapy for localised prostate cancer. Review of clinical trials. Clin Transl Oncol 2009, 11:437-445.

5. Grills IS, Martinez AA, Hollander M, Huang R, Goldman K, Chen PY, Gustafson GS: High dose rate brachytherapy as prostate cancer monotherapy reduces toxicity compared to low dose rate palladium seeds. J Urol 2004, 171:1098-1104.

6. Martinez AA, Demanes J, Vargas C, Schour L, Ghilezan M, Gustafson GS: High-Dose-Rate Prostate Brachytherapy: An Excellent AcceleratedHypofractionated Treatment for Favorable Prostate Cancer. Am J Clin Oncol 2010, 33(5):481-8.

7. Yoshioka Y, Konishi K, Oh RJ, Sumida I, Yamazaki H, Nakamura S, Nishimura K, Nonomura N, Okuyama A, Inoue T: High-dose-rate brachytherapy without external beam irradiation for locally advanced prostate cancer. Radiother Oncol 2006, 80:62-68.

8. Aluwini S, van Rooij P, Hoogeman M, Bangma C, Kirkels WJ, Incrocci L, Kolkman-Deurloo IK: CyberKnife stereotactic radiotherapy as monotherapy for low- to intermediate-stage prostate cancer: early experience, feasibility, and tolerance. J Endourol 2010, 24:865-869.

9. Friedland $J$, Freeman DE, Masterson-McGary ME, Spellberg DM: Stereotactic body radiotherapy: an emerging treatment approach for localized prostate cancer. Technol Cancer Res Treat 2009, 8:387-392.

10. Fuller DB, Naitoh J, Lee C, Hardy S, Jin H: Virtual HDR(SM) CyberKnife Treatment for Localized Prostatic Carcinoma: Dosimetry Comparison With HDR Brachytherapy and Preliminary Clinical Observations. Int J Radiat Oncol Biol Phys 2008, 70:1588-1597.

11. Katz AJ, Santoro M, Ashley R, Diblasio F, Witten M: Stereotactic body radiotherapy for organ-confined prostate cancer. BMC Urol 2010, 10:1.

12. King CR, Brooks JD, Gill H, Pawlicki T, Cotrutz C, Presti JC Jr: Stereotactic body radiotherapy for localized prostate cancer: interim results of a 
prospective phase II clinical trial. Int I Radiat Oncol Biol Phys 2009, 73:1043-1048

13. Madsen BL, Hsi RA, Pham HT, Fowler JF, Esagui L, Corman J: Stereotactic hypofractionated accurate radiotherapy of the prostate (SHARP), 33.5 Gy in five fractions for localized disease: first clinical trial results. Int $J$ Radiat Oncol Biol Phys 2007, 67:1099-1105.

14. Townsend NC, Huth BJ, Ding W, Garber B, Mooreville M, Arrigo S, Lamond J, Brady LW: Acute toxicity after CyberKnife-delivered hypofractionated radiotherapy for treatment of prostate cancer. Am $J$ Clin Oncol 2010.

15. Lloyd-Davies RW, Collins CD, Swan AV: Carcinoma of prostate treated by radical external beam radiotherapy using hypofractionation. Twenty-two years' experience (1962-1984). Urology 1990, 36:107-111.

16. Hossain S, Xia P, Chuang C, Verhey L, Gottschalk AR, Mu G, Ma L: Simulated real time image guided intrafraction tracking-delivery for hypofractionated prostate IMRT. Med Phys 2008, 35:4041-4048.

17. Hossain S, Xia P, Huang K, Descovich M, Chuang C, Gottschalk AR, Roach M, Ma L: Dose gradient gear target-normal structure interface for nonisocentric CyberKnife and isocentric intensity-modulated body radiotherapy for prostate cancer. Int I Radiat Oncol Biol Phys 2010.

18. Xie Y, Djajaputra D, King CR, Hossain S, Ma L, Xing L: Intrafractional motion of the prostate during hypofractionated radiotherapy. Int I Radiat Oncol Biol Phys 2008, 72:236-246.

19. Cox JD, Stetz J, Pajak TF: Toxicity criteria of the Radiation Therapy Oncology Group (RTOG) and the European Organization for Research and Treatment of Cancer (EORTC). Int I Radiat Oncol Biol Phys 1995, 31:1341-1346.

20. Abramowitz MC, Li T, Buyyounouski MK, Ross E, Uzzo RG, Pollack A, Horwitz EM: The Phoenix definition of biochemical failure predicts for overall survival in patients with prostate cancer. Cancer 2008, 112:55-60.

21. D'Amico AV, Whittington R, Kaplan I, Beard C, Schultz D, Malkowicz SB, Tomaszewski JE, Wein A, Coleman CN: Equivalent 5-year bNED in select prostate cancer patients managed with surgery or radiation therapy despite exclusion of the seminal vesicles from the CTV. Int I Radiat Oncol Biol Phys 1997, 39:335-340.

22. D'Amico AV, Whittington R, Malkowicz SB, Cote K, Loffredo M, Schultz D, Chen MH, Tomaszewski JE, Renshaw AA, Wein A, Richie JP: Biochemical outcome after radical prostatectomy or external beam radiation therapy for patients with clinically localized prostate carcinoma in the prostate specific antigen era. Cancer 2002, 95:281-286.

23. D'Amico AV, Whittington R, Malkowicz SB, Schultz D, Blank K, Broderick GA, Tomaszewski JE, Renshaw AA, Kaplan I, Beard CJ, Wein A: Biochemical outcome after radical prostatectomy, external beam radiation therapy, or interstitial radiation therapy for clinically localized prostate cancer. Jama 1998, 280:969-974.

24. Keyser D, Kupelian PA, Zippe CD, Levin HS, Klein EA: Stage T1-2 prostate cancer with pretreatment prostate-specific antigen level $<$ or $=10 \mathrm{ng} /$ ml: radiation therapy or surgery? Int I Radiat Oncol Biol Phys 1997, 38:723-729.

25. Kupelian PA, Potters L, Khuntia D, Ciezki JP, Reddy CA, Reuther AM, Carlson TP, Klein EA: Radical prostatectomy, external beam radiotherapy $<72 \mathrm{~Gy}$, external beam radiotherapy > or $=72 \mathrm{~Gy}$, permanent seed implantation, or combined seeds/external beam radiotherapy for stage T1-T2 prostate cancer. Int J Radiat Oncol Biol Phys 2004, 58:25-33.

26. Martinez AA, Gonzalez JA, Chung AK, Kestin LL, Balasubramaniam M Diokno AC, Ziaja EL, Brabbins DS, Vicini FA: A comparison of external beam radiation therapy versus radical prostatectomy for patients with low risk prostate carcinoma diagnosed, staged, and treated at a single institution. Cancer 2000, 88:425-432

27. King CR, Brooks JD, Gill H, Presti JCJ: Long-term outcomes from a prospective trial of stereotactic body radiotherapy for low-risk prostate cancer. Int J Radiat Oncol Biol Phys 2010

28. Aizer AA, Yu JB, Colberg JW, McKeon AM, Decker RH, Peschel RE: Radical prostatectomy vs. intensity-modulated radiation therapy in the management of localized prostate adenocarcinoma. Radiother Oncol 2009, 93:185-191.

29. Cahlon O, Zelefsky MJ, Shippy A, Chan H, Fuks Z, Yamada Y, Hunt M, Greenstein S, Amols H: Ultra-high dose (86.4 Gy) IMRT for localized prostate cancer: toxicity and biochemical outcomes. Int I Radiat Oncol Biol Phys 2008, 71:330-337.
30. Grimm PD, Blasko JC, Sylvester JE, Meier RM, Cavanagh W: 10-year biochemical (prostate-specific antigen) control of prostate cancer with (125)I brachytherapy. Int J Radiat Oncol Biol Phys 2001, 51:31-40.

31. Han M, Partin AW, Pound CR, Epstein Jl, Walsh PC: Long-term biochemical disease-free and cancer-specific survival following anatomic radical retropubic prostatectomy. The 15-year Johns Hopkins experience. Urol Clin North Am 2001, 28:555-565.

32. Kupelian PA, Thakkar W, Khuntia D, Reddy CA, Klein EA, Mahadevan A: Hypofractionated intensity-modulated radiotherapy (70 gy at 2.5 Gy per fraction) for localized prostate cancer: long-term outcomes. Int I Radiat Oncol Biol Phys 2005, 63:1463-1468.

33. Katz AJ, Santoro M: Quality of life and efficacy for stereotactic body radiotherapy for treatment of organ confined prostate cancer. Annual Meeting of the Association for Radiation Oncology. San Diego, CA 2010

34. Ponsky LE, Lillibridge C, Brindle J, Zhang Y, Wessels B, Einstein DB: Stereotactic robotic radiosurgery for localized prostate cancer: Initial evaluation of acute toxicities. 2009 ASCO Annual Meeting. Orlando, Florida 2009

35. Oermann E, Hanscom HS, Lei S, Suy S, Chen V, Collins BT, Dritschilo A, Lynch JH, Dawson NA, Collins SP: Hypofractionated robotic radiosurgery for the treatment of clinically localized prostate cancer: Early biochemical results and acute toxicity. 2010 ASCO Annual Meeting Chicago, IL 2010.

doi:10.1186/1748-717X-6-3

Cite this article as: Freeman and King: Stereotactic body radiotherapy for low-risk prostate cancer: five-year outcomes. Radiation Oncology 2011 6:3.

\section{Submit your next manuscript to BioMed Central and take full advantage of:}

- Convenient online submission

- Thorough peer review

- No space constraints or color figure charges

- Immediate publication on acceptance

- Inclusion in PubMed, CAS, Scopus and Google Scholar

- Research which is freely available for redistribution 